\title{
Gastric cancer: epidemiology, prevention, classification, and treatment
}

This article was published in the following Dove Press journal: Cancer Management and Research

\author{
Robert Sitarz ${ }^{1-3}$ \\ Małgorzata Skierucha ${ }^{1,2}$ \\ Jerzy Mielko' \\ G Johan A Offerhaus ${ }^{3}$ \\ Ryszard Maciejewski \\ Wojciech P Polkowski' \\ 'Department of Surgical Oncology, \\ Medical University of Lublin, Lublin, \\ Poland; ${ }^{2}$ Department of Human \\ Anatomy, Medical University of \\ Lublin, Lublin, Poland; ${ }^{3}$ Department of \\ Pathology, University Medical Centre, \\ Utrecht, The Netherlands
}

\begin{abstract}
Gastric cancer is the second most common cause of cancer-related deaths in the world, the epidemiology of which has changed within last decades. A trend of steady decline in gastric cancer incidence rates is the effect of the increased standards of hygiene, conscious nutrition, and Helicobacter pylori eradication, which together constitute primary prevention. Avoidance of gastric cancer remains a priority. However, patients with higher risk should be screened for early detection and chemoprevention. Surgical resection enhanced by standardized lymphadenectomy remains the gold standard in gastric cancer therapy. This review briefly summarizes the most important aspects of gastric cancers, which include epidemiology, risk factors, classification, diagnosis, prevention, and treatment. The paper is mostly addressed to physicians who are interested in updating the state of art concerning gastric carcinoma from easily accessible and credible source.
\end{abstract}

Keywords: gastric cancer, epidemiology, classification, risk factors, treatment

\section{Epidemiology}

Gastric carcinoma (GC) is the fourth most common malignancy worldwide $(989,600$ new cases per year in 2008) and remains the second cause of death $(738,000$ deaths annually) of all malignancies worldwide. ${ }^{1,2}$ The disease becomes symptomatic in an advanced stage. Five-year survival rate is relatively good only in Japan, where it reaches $90 \% .{ }^{3}$ In European countries, survival rates vary from $\sim 10 \%$ to $30 \%{ }^{4}$ High survival rate in Japan is probably achieved by early diagnosis by endoscopic examinations and consecutive early tumor resection.

The incidence shows wide geographical variation. More than $50 \%$ of the new cases occur in developing countries. There is a 15-20-fold variation in risk between the highest- and the lowest-risk populations. The high-risk areas are East Asia (China and Japan), Eastern Europe, Central and South America. The low-risk areas are Southern Asia, North and East Africa, North America, Australia, and New Zealand. ${ }^{3}$

Steady declines in GC incidence rates have been observed worldwide in the last few decades. ${ }^{3}$ This trend applies particularly to young patients with noncardia, sporadic, intestinal type of GC, as reported in the Japanese analysis., ${ }^{5,6}$ On the other hand, the American study differentiates race and age subpopulations, as well as the anatomic subtype of corpus gastric cancer, which have an increasing tendency. ${ }^{7}$ Nevertheless, the general declining incidence of GC may be explained by higher standards of hygiene, improved food conservation, a high intake of fresh fruits and vegetables, and by Helicobacter pylori (H. pylori) eradication. ${ }^{8}$
Correspondence: Robert Sitarz Department of Surgical Oncology, Medical University of Lublin, ul. Staszica II, 20-08I Lublin, Poland

$\mathrm{Tel}+488 \mathrm{I} 5344313$

Fax +48 8I 5322395

Email r.sitarz@umlub.pl 


\section{Conclusions relating to the epidemiology}

- GC detected at the stage $>\mathrm{T} 1 \mathrm{~N} 0$ has a poor prognosis.

- The incidence of GC varies geographically.

- Within the last few decades, the incidence of GC has steadily declined.

\section{Risk factors and prevention of gastric cancer}

Gastric cancer results from a combination of environmental factors and accumulation of specific genetic alterations. Despite declining trends worldwide, prevention of GC should remain a priority. The primary prevention includes healthy diet, anti-H. pylori therapies, chemoprevention, and screening for early detection. Dietary factors have an important impact on gastric carcinogenesis, especially in case of intestinal adenocarcinoma. Healthy dietary habits, that is, high intake of fresh fruits and vegetables, Mediterranean diet, a low-sodium diet, salt-preserved food, red and high cured meat, sensible alcohol drinking, and maintaining a proper weight might be associated with a decreased risk of GC. . $^{9-11}$

The protective role of fresh fruits and dark green, light green, and yellow vegetables rich in B carotene, vitamin C, $\mathrm{E}$, and foliate is strongly emphasized, probably due to their antioxidant effect. B carotene seems to be the leading risk reducer. ${ }^{12}$

The beneficial influence of vitamin-rich diet seems to be particularly noticeable in case of earlier foliate and selenium deficiency. ${ }^{13,14}$

Nevertheless, the outcomes of various studies about anticancer properties of carotenoids, tocopherols, and retinoids are not always coherent. Therefore, the issue requires further investigations. ${ }^{15}$

Many studies have confirmed that tobacco smoking increases the risk of GC, both cardia and noncardia subtypes. ${ }^{16,17}$ It has been shown that the risk of GC is increased by $60 \%$ in male and $20 \%$ in female smokers compared to nonsmokers. The risk of GC is lower in former smokers compared with occasional smokers, and smokers with higher consumption of cigarettes ( $>20$ cigarettes per day) are at higher risk of GC. ${ }^{16}$

Alcohol consumption also predisposes to GC. ${ }^{18}$ The association between alcohol abuse and gastric cardia cancer was reported. ${ }^{19}$

GC has been found to be inversely related to socioeconomic status, so that high socioeconomic position is associated with a reduced risk of GC, particularly cardia and intestinal subtypes. ${ }^{20}$ Professions that are at higher risk of GC are minors, fishermen, machine operators, nurses, cooks, launderers, and dry cleaners as the main occupational exposures comprise dust, nitrogen oxides, N-nitroso compounds, and radiation. ${ }^{21-23}$

Marshal and Warren discovered the association between H. pylori and gastritis in $1982 .{ }^{24}$ In 1994, H. pylori was classified as a class I carcinogen by the International Agency for Research on Cancer. ${ }^{25}$ Next, it has been accused of being the main environmental factor causing GC. ${ }^{26,27}$ H. pylori infection is a common cause of gastrointestinal problems, but only a few infected patients develop a severe disease such as peptic ulcer $(10 \%-15 \%)$ or GC $(1 \%-3 \%){ }^{28}$

In the general population, $H$. pylori infection reaches $\sim 60 \%$, but in patients with GC, it is more common ( $84 \%$ ) or even inevitable (noncardia GC). ${ }^{29,30}$ The correlation between H. pylori infection and $\mathrm{GC}$ relates also to younger age $(<40$ years $)^{31}$ and is involved in both intestinal and diffuse types of noncardia GC. The latter is more common in early onset gastric cancer (EOGC)..$^{32,33}$

Undoubtedly, the strong correlation between H. pylori infection and GC is a possible target of intervention. ${ }^{25}$ The Maastricht III Guidelines recommend to treat the infection in peptic ulcer diseases, mucosa-associated lymphoid tissue lymphomas, atrophic gastritis, patients after resection of GC, first-degree relatives of GC patients, patients with unexplained iron deficiency anemia, patients with idiopathic thrombocytopenia purpura, patients who require long-term nonsteroidal anti-inflammatory drugs (NSAIDs), and in patients who just wish to be treated..$^{34}$ The first-line eradication treatment of H. pylori relies on proton pump inhibitors and combination of two antibiotics such as amoxicillin, clarithromycin, or metronidazole. If the first therapy does not succeed, then the proposed second-line treatment is bismuth salts, proton pomp inhibitor, tetracycline, and metronidazole. ${ }^{34}$

Epstein-Barr virus (EBV) is a human herpes virus for which a causal role in gastric carcinogenesis has been suggested. ${ }^{35}$ The association between EBV and carcinogenesis varies from 4\% in China, 7.7\% in France, $8.1 \%$ in Russia, $12.5 \%$ in Poland, to $17.9 \%$ in Germany. ${ }^{36,37}$ EBV in carcinoma biopsies indicates that the tumor has been formed by the proliferation of a single infected cell. ${ }^{37}$ In addition, EBV infection might be a late event in gastric carcinogenesis. ${ }^{38}$ Interestingly, EBV is more common in carcinomas in postsurgical gastric remnant (27\%) than in an intact stomach. ${ }^{39}$

Aspirin and NSAID users are shown to be at a reduced risk of GC. ${ }^{40}$ On the other hand, the side effects of these are bleeding, perforation, or gastric outlet obstruction, ${ }^{41}$ and therefore, these drugs are not recommended for patients with 
a history of digestive complaints. ${ }^{42}$ In the late 1990 s, there was an impermanent enthusiasm for the COX-2-selective NSAIDs, but shortly after, they were accused of increasing risk of myocardial infarction. ${ }^{43}$

Familial clustering of $\mathrm{GC}$ has been reported for centuries and the world-famous example is the family of Napoleon Bonaparte. ${ }^{44-46}$ In 1998, truncating mutations of $\mathrm{CDH1}$ were described in the germline of three New Zealand Maori families predisposed to diffuse GC. ${ }^{45}$ In general, the risk of developing GC is calculated to be 1.5-3 fold increased in individuals with a family history of GC. ${ }^{44}$

Obesity is a risk factor for gastric cardia carcinomas. ${ }^{47}$ Less common risk factors include pernicious anemia, blood type A. ${ }^{48,49}$ Gastrectomy is also a risk factor for gastric cancer, a long time after partial gastrectomy. ${ }^{50}$

Endoscopy is the most sensitive and specific diagnostic screening method. ${ }^{51}$ However, mass screening for early detection of GC is expensive, and therefore, recommended only in regions with high incidence, such as East Asia, and senseless in low-incidence regions, such as North America. 52,53

Additionally, endoscopic surveillance should be performed one to two times per year in patients who are at higher risk of GC (history of GC in family, familial adenomatous polyposis, Li-Fraumeni syndrome, BRCA2 mutations, hereditary nonpolyposis colon cancer syndrome, Peutz-Jeghers syndrome, and Ménétrier disease, previous gastric surgery, gastric polyps). ${ }^{52,54}$

\section{Conclusions relating to risk factors and prevention}

1. Early detection of both changeable and unchangeable GC risk factors is vital in primary prevention.

2. Changeable risk factors accounting for gastric cancer incidence are as follows:

a. Patient dependent: maintaining balanced diet, moderate alcohol intake, giving up smoking, and keeping normal weight.

b. Doctor dependent: H. pylori eradication, considering NSAIDs.

3. Unchangeable risk factors of GC are occupational exposures, family history of GC, comorbidities, and history of partial gastrectomy.

\section{Classification of gastric cancer Sporadic gastric cancer}

The majority of GC occurs sporadically and mainly affects people over the age of 45 years. These carcinomas are termed as "sporadic gastric cancers" (SGCs) (Figure 1). ${ }^{55}$ They are commonly caused by coincidence of many environmental

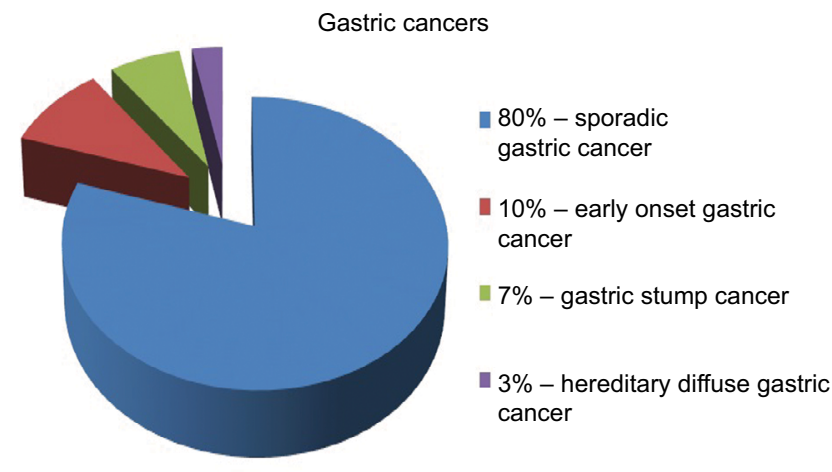

Figure I Classification of gastric cancers.

Notes: Adapted from Skierucha M, Milne AN, Offerhaus G], Polkowski WP, Maciejewski R, Sitarz R. Molecular alterations in gastric cancer with special reference to the early-onset subtype. World J Gastroenterol. 2016;22(8):2460-2474. Copyright (The Author(s) 2016. Published by Baishideng Publishing Group Inc. All rights reserved. ${ }^{55}$

factors. ${ }^{56}$ They occur at the age of 60-80 years, and males are two times more often affected than females, particularly in high-risk countries. ${ }^{57}$

\section{Early onset gastric cancer}

EOGC is defined as GC before the age of 45 years and encompasses about $10 \%$ of GCs (Figure 1). ${ }^{55,58}$ In EOGCs, genetic factors seem to play the causal role. ${ }^{56}$ These cancers are often multifocal, diffuse, and are more frequently observed in females, probably because of hormonal factors. ${ }^{56,59-62} \mathrm{SGC}$ and EOGC vary as well at the molecular level..$^{55,63}$ Nevertheless, apart from the cases of hereditary GC, the pathogenesis of EOGC still remains unclear.

\section{Gastric stump cancer}

Gastric stump cancer (GSC) is a separate subtype of GC, defined as a carcinoma that occurs in the gastric remnant at least 5 years after the surgery for peptic ulcer. ${ }^{64}$ GSC represents from $1.1 \%$ to $7 \%$ of all GCs (Figure 1), and males are more prone to them than woman. ${ }^{55,65,66}$ Gastrectomy is a well-established risk factor for GSC, even long time after the initial surgery. ${ }^{50,67}$ After 15 years from the gastrectomy, the risk of GSC is increased four- to sevenfold compared with the healthy population. ${ }^{50,68} \mathrm{EBV}$ infection is more often in gastric remnants than in intact stomachs. ${ }^{39}$ The virus may interact with the $\mathrm{p} 53$ protein. ${ }^{69}$ In contrast, H. pylori infection in GSCs is less frequent. ${ }^{70}$ GSCs are commonly preceded by well-defined precursor lesions, mostly by dysplasia, and therefore, endoscopic surveillance with multiple biopsies of the gastroenterostoma is recommended..$^{71}$

\section{Hereditary diffuse gastric cancer (HDGC)} Most cases of GCs appear sporadically, but in 5\%-10\% of cases, familial clustering is observed. ${ }^{44}$ HDGC concerns 
$1 \%-3 \%$ of all GCs (Figure 1). ${ }^{55,72}$ HDGCs result from inherited syndromes, one of which are germline mutations in the $\mathrm{CDH} 1$ gene that encodes E-cadherin. These are autosomal dominant conditions that cause diffuse, poorly differentiated GC, which infiltrates into stomach wall and causes thickening of the wall without forming a distinct mass.

\section{Conclusions related to classification}

- Eighty percent of GCs are SGCs. They occur mostly in elderly males, who come from high-risk area and have been exposed to environmental risk factors.

- Ten percent of gastric cancers are EOGCs. They occur at the age $<45$ years, more frequently in females.

- Seven percent of gastric cancers are GSCs. Most of them are preceded by dysplasia. The risk of them rises within time after gastrectomy.

- Three percent of gastric cancers are HGDCs. They are inherited by autosomal dominant mutation of $\mathrm{CDH} 1$ gene.

\section{Pathological classification}

According to the World Health Organization guidelines, GC can be classified as adenocarcinoma, signet ring-cell carcinoma, and undifferentiated carcinoma. However, it is not as widely used as the Lauren classification, which distinguishes two major subtypes of GC, intestinal and diffuse types. ${ }^{73}$ The Lauren classification contains microscopic and macroscopic differences. ${ }^{73}$ It has been postulated that intestinal types of GC are associated with chronic atrophic gastritis and intestinal metaplasia, whereas diffuse types originate from normal gastric mucosa. The ratio of intestinal and diffuse types varies between countries and continents. In European countries, intestinal type is currently more common. ${ }^{74-78}$ It tends to occur more often in the distal stomach, in high-risk areas, and it is often preceded by a long-standing precancerous lesion. ${ }^{75}$ The diffuse type prevails among young patients. The extent of the surgical resection depends on the Lauren's histological subtype of GCs.

\section{Conclusions relating to the pathological classification}

- GC is mostly divided into two subtypes: intestinal and diffuse ones.

- Extent of surgical resection depends on histopathological outcome.

\section{Treatment}

Multidisciplinary approach for the planning of the GC treatment is mandatory. The multidisciplinary team (MDT) should include at least a surgeon, pathologist, gastroenterologist, medical and radiation oncologists. ${ }^{79}$ In case of curative intention, the surgery involves complete resection with a standardized D2 lymphadenectomy. ${ }^{80}$ In 1998, Japanese Gastric Cancer Association (JGCA) standardized the regional lymphadenectomy based on the location of the tumor and the respective regional node drainage. Sixteen different lymph node stations around the stomach have been recognized. The lymph node stations along the lesser curvature (stations 1, 3, and 5) and the greater curvature (stations 2, 4, and 6) of the stomach have been grouped as N1. The nodes along the left gastric artery (station 7), the common hepatic artery (station 8), the celiac artery (station 9), and the splenic artery (stations 10 and 11) have been grouped as $\mathrm{N} 2$. N3 group has encompassed the lymph nodes along the hepatoduodenal ligament (station 12), at the posterior site of the pancreas (station 13), and at the root of the mesentery (station 14). Finally, the lymph nodes around the middle colic artery (station 15) and lower paraesophageal lymph node and diaphragmatic lymph (station 16) have been grouped as N4. ${ }^{81} \mathrm{D} 1, \mathrm{D} 2$, and D3 are the names given to the procedures that depend on the range of lymphadenectomy. ${ }^{81}$ However, the seventh edition of TNM classification and a new version of the JGCA classification cancer of the stomach changed the definitions of D1/D2 lymphadenectomy according to the extent of gastric resection (Table 1) ${ }^{82}$ Endoscopic mucosal resection (EMR) in early GC treatment (T1aNOM0) and in intraepithelial neoplasia can provide the same effect as traditional surgical resection. ${ }^{83,84}$ For well-differentiated types of mucosal tumors, endoscopic submucosal dissection (ESD) is often successful. ${ }^{84,85}$ Splenectomy is acceptable only in the case of the direct cancer infiltration of the splenic hilum. ${ }^{86}$ Advanced gastric tumors with distant metastasis are usually incurable; however, it does not concern cases with solitary liver metastasis or peritoneal nodules invasion. For incurable GC patients, palliative resection may improve the quality of life, but it is not recommended in an asymptomatic patients. ${ }^{87}$ Histological examination after regional lymphadenectomy should include more than 15 lymph nodes. Treatment recommendations of the JGCA (fourth edition from 2014) are presented in Table $2 .{ }^{82}$

The high incidence of distant metastases and the local recurrence after have paved the way for systemic therapy, and recently in neo-adjuvant therapy. ${ }^{88}$ The extensive treatment may include chemotherapy, radiation therapy or immunotherapy, either alone or in combinations. Adjuvant therapy has been shown to be beneficial in GC. ${ }^{89,90}$ Recent studies have revealed the superiority of the neoadjuvant therapy 
Table I Extent of lymphadenectomy according to the type of gastric resection

\begin{tabular}{|c|c|c|c|}
\hline Gastrectomy & DI & DI+ & D2 \\
\hline Distal resection of the stomach & $\mathrm{I}, 3,4,5,6,7$ & $(\mathrm{DI})+8,9$ & $(\mathrm{DI})+8,9, \mathrm{II}, 12$ \\
\hline Total gastrectomy & $\mathrm{I}-7$ (2 included $)$ & $(\mathrm{DI})+8,9, \mathrm{II}$ & $(D I)+8,9,10,11,12$ \\
\hline
\end{tabular}

Note: Data from Japanese Gastric Cancer Association. ${ }^{82}$

Abbreviations: DI, DI lymphadenectomy; DI+, expanded DI lymphadenectomy; D2, D2 lymphadenectomy.

\begin{tabular}{|l|l|l|l|l|}
\hline & N0 & N1 (1-2) & N2 (3-6) & N3 (>7) \\
\hline T1a & $\begin{array}{l}\text { ESD/EMR } \\
\text { (G1, }<2 \mathrm{~cm}, \\
\text { not ulcerated })\end{array}$ & D2 & D2 and ACT & D2 and ACT \\
\hline T1b & D1+ and sentinel & D2 & D2 and ACT & D2 and ACT \\
\hline T2 & D2 & D2 and ACT & D2 and ACT & D2 and ACT \\
\hline T3 & D2 and ACT & D2 and ACT & D2 and ACT & D2 and ACT \\
\hline T4a & D2 and ACT & D2 and ACT & D2 and ACT & D2 and ACT \\
\hline T4b & $\begin{array}{l}\text { D2 + extended } \\
\text { resection + ACT }\end{array}$ & $\begin{array}{l}\text { D2 + extended } \\
\text { resection + ACT }\end{array}$ & $\begin{array}{l}\text { D2 + extended } \\
\text { resection + ACT }\end{array}$ & D2 + extended \\
resection + ACT
\end{tabular}

Table 2 The JGCA cancer classification according to the extent of gastric resection and DI/D2 lymphadenectomy.

Notes: Recently, chemotherapeutic regimens for HER2-positive gastric cancer should include trastuzumab, and the efficacy of ramucirumab has proved as a second-line chemotherapy for recurrent or metastatic gastric cancers. Data from Japanese Gastric Cancer Association. ${ }^{82}$

Abbreviations: ACT, adjuvant chemotherapy; DI, DI lymphadenectomy; DI+, expanded DI lymphadenectomy; D2, D2 lymphadenectomy; ESD, endoscopic submucosal dissection; EMR, endoscopic mucosal resection; extended resection, extended resection of the adjacent organs; GI, grade I; JGCA, Japanese Gastric Cancer Association; sentinel, sentinel lymph node mapping; $N$, extent of nodule invasion; $\mathrm{T}$, tumor stage.

combined with surgery over the surgery alone, with 5-years progression-free rate at $23 \%-36 \% .{ }^{91}$ Palliative chemotherapy or surgery is recommended in patients with metastases, but in a good general condition. In case of patients with poor performance status, the supportive treatment is the only recommendation. ${ }^{86}$ Management algorithm for patients in a good general condition without distant metastases (M0) is shown in Figure 2. ${ }^{92}$

\section{Chemotherapy}

Two randomized trials have shown an improvement in overall survival in patients receiving perioperative chemotherapy. ${ }^{91,93}$ Such a treatment is, therefore, routinely performed in Europe and includes three cycles of chemotherapy before surgery and three cycles after surgery. ${ }^{94}$

\section{Neo-adjuvant (chemo-)radiotherapy}

The results of the INT 0116 trial have shown the effectiveness of adjuvant radiotherapy and chemotherapy compared with surgery alone. Three-year observation has shown an $11 \%$ improvement in overall survival after combined treatment, with a median survival of 36 months. It has been compared with only 27 months of survival after surgery alone. The median recurrence-free survival time has been 30 months in the chemo-radiotherapy group and 19 months in the surgery alone group. ${ }^{95}$

Although adjuvant radiotherapy and chemotherapy is recommended in the United States, in the European countries, the treatment has been limited to cases with suboptimal lymphadenectomy (removal of $<15$ lymph nodes) or irradical microscopic resection (R1) of the stomach. ${ }^{96}$ Application of adjuvant chemo-radiotherapy after D1 lymphadenectomy reduces the incidence of local recurrence and improves survival of the patients..$^{97,98}$

The results of perioperative chemotherapy in patients with GC and gastro-esophageal junction are promising. ${ }^{91,93}$ A statistically significant improvement of overall survival and progression-free survival has been observed in $36 \%$ of patients with perioperative chemotherapy compared with $23 \%$ after the operation alone. ${ }^{91}$ Therefore, perioperative 


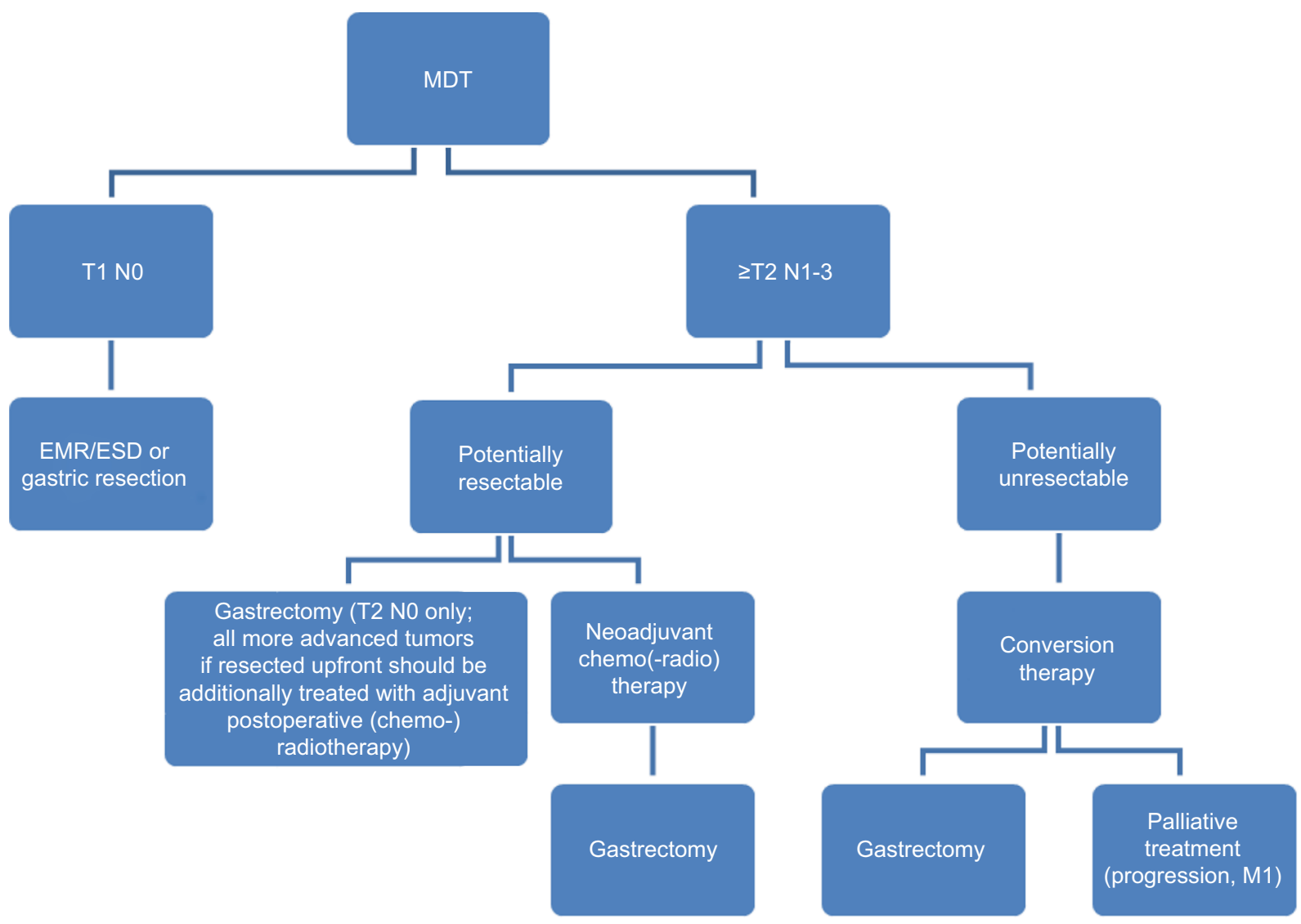

Figure 2 Management algorithm for patients in good performance status and without distant metastases (M0).

Notes: Modified with permission from Polkowski W, Łacko A, Guzel Z. Nowotwory żołądka [Gastric cancers]. In: Krzakowski M, Warzecha K, editors. Zalecenia postępowania diagnostyczno-terapeutycznego w nowotworach złośliwych - 2013 rok [Recommendations for Diagnostics and Treatment of Malignant Neoplasms - 20I3]. Gdansk: Via Medica; 2013:119. Copyright (C) 2013 Via Medica. ${ }^{92}$

Abbreviations: EMR, endoscopic mucosal resection; ESD, endoscopic submucosal dissection; MDT, multidisciplinary team.

chemotherapy plus radical surgery has been recommended as a standard treatment for locally advanced tumors. ${ }^{99,100}$

Combination of regiments bases traditionally upon a platinum-fluoropyrimidine doublet, but adding an anthracycline has been shown to be beneficial. ${ }^{101}$ The most commonly used protocols are ECF (epirubicin, cisplatin, 5-FU), ECX (epirubicin, cisplatin, capecitabine), EOF (epirubicin, oxaliplatin, 5-FU), and EOX (epirubicin, oxaliplatin, capecitabine). Alternatively, chemonaive patients might be treated with taxane-based or irinotecan/5-fluorouracil regiments. ${ }^{94,102}$

Second-line therapy bases on irinotecan, docetaxel, and paclitaxel. ${ }^{103-106}$ However, in case of late disease progression after first-line chemotherapy (after $>3$ months), it might be beneficial to try the same drugs again. ${ }^{94}$

Despite the improvement in overall survival after neoadjuvant chemotherapy, high occurrence of relapses are still observed. Therefore, addition of radiotherapy in preoperative setting may be beneficial. Radiotherapy is well tolerated, improves the resectability of the tumor, and does not increase the frequency of surgical complications. Currently, adjuvant radio-chemotherapy is recommended in patients with loco-regionally advanced carcinoma of the gastro-esophageal junction (T2N1-3M0 or T3N0-3M0). ${ }^{107}$

\section{Palliative radiotherapy}

Radiotherapy is justified in cases of unresectable GC with ane$\mathrm{mia}$, and/or in the cases with pyloric or cardiac obstruction. The dose of 30 Gy in 10 fractions can be effective both in diminishing bleeding and in improving the food passage. The effect is usually short (3-6 months), but it is an easy therapeutic option. ${ }^{108,109}$

\section{Treatment of gastric cancer in the metastatic setting}

Compared with symptomatic treatment, palliative chemotherapy for patients with inoperable GC prolongs survival and improves its quality. In 2010, the US Food and Drug Administration approved "trastuzumab", a monoclonal antibody that interferes with the HER2 receptor, for the treatment of locally advanced and metastatic GC. Following the results of the ToGA trial, "trastuzumab" in combination with capecitabine or 5-FU and cisplatin is now the standard of care for HER2-positive GCs. ${ }^{82,110}$ 
Second-line chemotherapies base on the regimens with a taxane (docetaxel, paclitaxel), or irinotecan, or ramucirumab as single agent or in combination with paclitaxel. Ramucirumab is the anti-vascular endothelial growth factor receptor- 2 monoclonal antibody that has been associated with a survival benefit compared with cytotoxic chemotherapy in the second-line setting. Ramucirumab in addition to paclitaxel has correlated with a survival benefit compared with paclitaxel alone. . $2,11,112^{2}$

However, chemotherapy may be used only in patients with good performance status (PS 0-1). ${ }^{82}$ Cytoreductive surgery plus hyperthermic intraperitoneal chemotherapy improves survival in a group of highly selected patients with limited peritoneal carcinomatosis of gastric origin (peritoneal cancer index $<12) .{ }^{113,114}$

\section{Conclusions relating to treatment}

- Operation range depends on the stage of the disease, and it is described in recommendations from 2010 (Figure 2).

- Systematic therapy improves long-term, progression-free survival rate in comparison with surgical treatment alone.

- Palliative chemotherapy in patients with inoperable gastric cancer prolongs survival and improves the quality of life.

\section{Conclusion}

$\mathrm{GC}$ is a malignant disease with a generally poor long-term prognosis. The majority of GCs are sporadic subtypes that are strongly associated with environmental risk factors. In the last decades, some mechanisms of gastric cancerogenesis have been elucidated, which has resulted in the primary and secondary prevention, such as healthy lifestyle and $H$. pylori eradication. Consequently, the incidence of gastric cancer has started to decline. This tendency does not concern the GC subtypes that result from genetic predisposition or comorbidities. Nevertheless, the endoscopic surveillance program is recommended for screening a group of patients with the highest risk of GC.

Every patient with GC needs to be treated according to the individual plan made by MDT. The planning strategy should consider: stage of the tumor, intention of the therapy, patient's performance status, and technical possibilities. Generally, the most beneficial approach seems to be surgery combined with chemotherapy and radiotherapy.

\section{Disclosure}

The authors report no conflicts of interest in this work.

\section{References}

1. Wright NA, Poulsom R, Stamp G, et al. Trefoil peptide gene expression in gastrointestinal epithelial cells in inflammatory bowel disease. Gastroenterology. 1993;104(1):12-20.

2. Jemal A, Bray F, Center MM, Ferlay J, Ward E, Forman D. Global cancer statistics. CA Cancer J Clin. 2011;61(2):69-90.

3. Stock M, Otto F. Gene deregulation in gastric cancer. Gene. 2005;360(1) $1-19$.

4. Parkin DM, Bray F, Ferlay J, Pisani P. Global cancer statistics 2002. CA Cancer J Clin. 2005;55(2):74-108.

5. Kaneko S, Yoshimura T. Time trend analysis of gastric cancer incidence in Japan by histological types, 1975-1989. Br JCancer. 2001;84(3):400-405.

6. Bertuccio P, Chatenoud L, Levi F, et al. Recent patterns in gastric cancer: a global overview. Int J Cancer. 2009;125(3):666-673.

7. Camargo MC, Anderson WF, King JB, et al. Divergent trends for gastric cancer incidence by anatomical subsite in US adults. Gut. 2011;60(12):1644-1649.

8. Munoz N, Franceschi S. Epidemiology of gastric cancer and perspectives for prevention. Salud Publica Mex. 1997;39(4):318-330.

9. Buckland G, Travier N1, Huerta JM, et al. Healthy lifestyle index and risk of gastric adenocarcinoma in the EPIC cohort study. Int J Cancer. 2015;137(3):598-606.

10. Lin SH, Li YH, Leung K, Huang CY, Wang XR. Salt processed food and gastric cancer in a Chinese population. Asian Pac J Cancer Prev. 2014;15(13):5293-5298.

11. Massarrat S, Stolte M. Development of gastric cancer and its prevention. Arch Iran Med. 2014;17(7):514-520.

12. Nomura AM, Hankin JH, Kolonel LN, Wilkens LR, Goodman MT, Stemmermann GN. Case-control study of diet and other risk factors for gastric cancer in Hawaii (United States). Cancer Causes Control. 2003;14(6):547-558.

13. Tavani A, Malerba S, Pelucchi C, et al. Dietary folates and cancer risk in a network of case-control studies. Ann Oncol. 2012;23(10):2737-2742.

14. Camargo MC, Burk RF, Bravo LE, et al. Plasma selenium measurements in subjects from areas with contrasting gastric cancer risks in Colombia. Arch Med Res. 2008;39(4):443-451.

15. Jenab M, Riboli E, Ferrari P, et al. Plasma and dietary carotenoid, retinol and tocopherol levels and the risk of gastric adenocarcinomas in the European prospective investigation into cancer and nutrition. Br J Cancer. 2006;95(3):406-415.

16. Ladeiras-Lopes R, Pereira AK, Nogueira A, et al. Smoking and gastric cancer: systematic review and meta-analysis of cohort studies. Cancer Causes Control. 2008;19(7):689-701.

17. Nishino Y, Inoue M, Tsuji I, et al; Research Group for the Development and Evaluation of Cancer Prevention Strategies in Japan. Tobacco smoking and gastric cancer risk: an evaluation based on a systematic review of epidemiologic evidence among the Japanese population. Jpn J Clin Oncol. 2006;36(12):800-807.

18. Jedrychowski W, Wahrendorf J, Popiela T, Rachtan J. A case-control study of dietary factors and stomach cancer risk in Poland. Int J Cancer. 1986;37(6):837-842.

19. Lagergren J, Bergström R, Lindgren A, Nyrén O. The role of tobacco, snuff and alcohol use in the aetiology of cancer of the oesophagus and gastric cardia. Int J Cancer. 2000;85(3):340-346.

20. Nagel G, Linseisen J, Boshuizen HC, et al. Socioeconomic position and the risk of gastric and oesophageal cancer in the European Prospective Investigation into Cancer and Nutrition (EPIC-EURGAST). Int J Epidemiol. 2007;36(1):66-76.

21. Cocco P, Palli D, Buiatti E et al. Occupational exposures as risk factors for gastric cancer in Italy. Cancer Causes Control. 1994;5(3):241-248.

22. Simpson J, Roman E, Law G, Pannett B. Women's occupation and cancer: preliminary analysis of cancer registrations in England and Wales, 1971-1990. Am J Ind Med. 1999;36(1):172-185.

23. Aragones N, Pollan M, Gustavsson P. Stomach cancer and occupation in Sweden: 1971-89. Occup Environ Med. 2002;59(5):329-337. 
24. Warren JR, Marshall B. Unidentified curved bacilli on gastric epithelium in active chronic gastritis. Lancet. 1983;1(8336):1273-1275.

25. IARC Working Group on the Evaluation of Carcinogenic Risks to Humans. Lyon, 7-14 June 1994. Schistosomes, liver flukes and Helicobacter pylori. IARC Monogr Eval Carcinog Risks Hum. 1994;61: $1-241$.

26. Forman D, Newell DG, Fullerton F, et al. Association between infection with Helicobacter pylori and risk of gastric cancer: evidence from a prospective investigation. BMJ. 1991;302(6788):1302-1305.

27. Parsonnet J, Samloff IM, Nelson LM, Orentreich N, Vogelman $\mathrm{JH}$, Friedman GD. Helicobacter pylori, pepsinogen, and risk for gastric adenocarcinoma. Cancer Epidemiol Biomarkers Prev. 1993;2(5):461-466.

28. Suerbaum S, Michetti P. Helicobacter pylori infection. $N$ Engl J Med. 2002;347(15):1175-1186.

29. Parsonnet J, Friedman GD, Vandersteen DP. Helicobacter pylori infection and the risk of gastric carcinoma. $N$ Engl $J$ Med. 1991;325(16):1127-1131.

30. González CA, Megraud F, Buissonniere A, et al. Helicobacter pylori infection assessed by ELISA and by immunoblot and noncardia gastric cancer risk in a prospective study: the Eurgast-EPIC project. Ann Oncol. 2012;23(5):1320-1324.

31. Masuda G, Tokunaga A, Shirakawa T, et al. Helicobacter pylori infection, but not genetic polymorphism of CYP2E1, is highly prevalent in gastric cancer patients younger than 40 years. Gastric Cancer. 2007;10(2):98-103.

32. Correa P, Houghton J. Carcinogenesis of Helicobacter pylori. Gastroenterology. 2007;133(2):659-672.

33. Rugge M, Busatto G, Cassaro M, et al. Patients younger than 40 years with gastric carcinoma: Helicobacter pylori genotype and associated gastritis phenotype. Cancer. 1999;85(12):2506-2511.

34. Malfertheiner P, Megraud F, O'Morain C, et al. Current concepts in the management of Helicobacter pylori infection: the Maastricht III Consensus Report. Gut. 2007;56(6):772-781.

35. Imai S, Koizumi S, Sugiura M, et al. Gastric carcinoma: monoclonal epithelial malignant cells expressing Epstein-Barr virus latent infection protein. Proc Natl Acad Sci U S A. 1994;91(19):9131-9135.

36. Czopek JP, Stojak M, Sińczak A, et al. EBV-positive gastric carcinomas in Poland. Pol J Pathol. 2003;54(2):123-128.

37. Takada K. Epstein-Barr virus and gastric carcinoma. Mol Pathol. 2000;53(5):255-261.

38. Zur Hausen A, van Rees BP, van Beek J, et al. Epstein-Barr virus in gastric carcinomas and gastric stump carcinomas: a late event in gastric carcinogenesis. J Clin Pathol. 2004;57(5):487-491.

39. Yamamoto N, Tokunaga M, Uemura Y, et al. Epstein-Barr virus and gastric remnant cancer. Cancer. 1994;74(3):805-809.

40. Wang WH, Huang JQ, Zheng GF, Lam SK, Karlberg J, Wong BC. Non-steroidal anti-inflammatory drug use and the risk of gastric cancer: a systematic review and meta-analysis. $J$ Natl Cancer Inst. 2003;95(23):1784-1791.

41. Harbison SP, Dempsey DT. Peptic ulcer disease. Curr Probl Surg. 2005;42(6):346-454.

42. Farrow DC, Vaughan TL, Hansten PD, et al. Use of aspirin and other nonsteroidal anti-inflammatory drugs and risk of esophageal and gastric cancer. Cancer Epidemiol Biomarkers Prev. 1998;7(2): 97-102.

43. Bombardier C, Laine L, Reicin A, et al; VIGOR Study Group. Comparison of upper gastrointestinal toxicity of rofecoxib and naproxen in patients with rheumatoid arthritis. VIGOR Study Group. $N$ Engl $J$ Med. 2000;343(21):1520-1528.

44. La Vecchia C, Negri E, Franceschi S, Gentile A. Family history and the risk of stomach and colorectal cancer. Cancer. 1992;70(1):50-55.

45. Guilford P, Hopkins J, Harraway J, et al. E-cadherin germline mutations in familial gastric cancer. Nature. 1998;392(6674):402-405.

46. Sokoloff B. Predisposition to cancer in the Bonaparte family. Am J Surg. 1938;40(3):673-678.
47. Vaughan TL, Davis S, Kristal A, Thomas DB. Obesity, alcohol, and tobacco as risk factors for cancers of the esophagus and gastric cardia: adenocarcinoma versus squamous cell carcinoma. Cancer Epidemiol Biomarkers Prev. 1995;4(2):85-92.

48. Hsing AW, Hansson LE, McLaughlin JK, et al. Pernicious anemia and subsequent cancer. A population-based cohort study. Cancer. 1993;71(3):745-750.

49. Aird I, Bentall HH, Roberts JA. A relationship between cancer of stomach and the ABO blood groups. Br Med J. 1953;1(4814):799-801.

50. Offerhaus GJ, Tersmette AC, Huibregtse K, et al. Mortality caused by stomach cancer after remote partial gastrectomy for benign conditions: 40 years of follow up of an Amsterdam cohort of 2633 postgastrectomy patients. Gut. 1988;29(11):1588-1590.

51. Tashiro A, Sano M, Kinameri K, Fujita K, Takeuchi Y. Comparing mass screening techniques for gastric cancer in Japan. World J Gastroenterol. 2006;12(30):4873-4874.

52. Leung WK, Wu MS, Kakugawa Y, et al. Screening for gastric cancer in Asia: current evidence and practice. Lancet Oncol. 2008;9(3):279-287.

53. Dicken BJ, Bigam DL, Cass C, Mackey JR, Joy AA, Hamilton SM. Gastric adenocarcinoma: review and considerations for future directions. Ann Surg. 2005;241(1):27-39.

54. Hirota WK, Zuckerman MJ, Adler DG, et al; Standards of Practice Committee, American Society for Gastrointestinal Endoscopy. ASGE guideline: the role of endoscopy in the surveillance of premalignant conditions of the upper GI tract. Gastrointest Endosc. 2006;63(4):570-580.

55. Skierucha M, Milne AN, Offerhaus GJ, Polkowski WP, Maciejewski R, Sitarz R. Molecular alterations in gastric cancer with special reference to the early-onset subtype. World $J$ Gastroenterol. 2016;22(8):2460-2474.

56. Kikuchi S, Nakajima T, Nishi T, et al. Association between family history and gastric carcinoma among young adults. Jpn J Cancer Res. 1996;87(4):332-336.

57. Forman D, Burley VJ. Gastric cancer: global pattern of the disease and an overview of environmental risk factors. Best Pract Res Clin Gastroenterol. 2006;20(4):633-649.

58. Kokkola A, Sipponen P. Gastric carcinoma in young adults. Hepatogastroenterology. 2001;48(42):1552-1555.

59. Hayden JD, Cawkwell L, Sue-Ling H, et al. Assessment of microsatellite alterations in young patients with gastric adenocarcinoma. Cancer. 1997;79(4):684-687.

60. Lim S, Lee HS, Kim HS, Kim YI, Kim WH. Alteration of E-cadherinmediated adhesion protein is common, but microsatellite instability is uncommon in young age gastric cancers. Histopathology. 2003;42(2):128-136.

61. Ramos-De la Medina A, Salgado-Nesme N, Torres-Villalobos G, Medina-Franco H. Clinicopathologic characteristics of gastric cancer in a young patient population. J Gastrointest Surg. 2004;8(3):240-244.

62. Maeta M, Yamashiro H, Oka A, Tsujitani S, Ikeguchi M, Kaibara N. Gastric cancer in the young, with special reference to 14 pregnancyassociated cases: analysis based on 2,325 consecutive cases of gastric cancer. J Surg Oncol. 1995;58(3):191-195.

63. Milne AN, Carvalho R, Morsink FM, et al. Early-onset gastric cancers have a different molecular expression profile than conventional gastric cancers. Mod Pathol. 2006;19(4):564-572.

64. Thorban S, Böttcher K, Etter M, Roder JD, Busch R, Siewert JR. Prognostic factors in gastric stump carcinoma. Ann Surg. 2000;231(2): 188-194.

65. Sons HU, Borchard F. Gastric carcinoma after surgical treatment for benign ulcer disease: some pathologic-anatomic aspects. Int Surg. 1987;72(4):222-226.

66. Sinning C, Schaefer N, Standop J, Hirner A, Wolff M. Gastric stump carcinoma - epidemiology and current concepts in pathogenesis and treatment. Eur J Surg Oncol. 2007;33(2):133-139.

67. Toftgaard C. Gastric cancer after peptic ulcer surgery. A historic prospective cohort investigation. Ann Surg. 1989;210(2):159-164. 
68. Tersmette AC, Goodman SN, Offerhaus GJ, et al. Multivariate analysis of the risk of stomach cancer after ulcer surgery in an Amsterdam cohort of postgastrectomy patients. Am J Epidemiol. 1991;134(1):14-21.

69. van Rees BP, Caspers E, zur Hausen A, et al. Different pattern of allelic loss in Epstein-Barr virus-positive gastric cancer with emphasis on the p53 tumor suppressor pathway. Am J Pathol. 2002;161(4):1207-1213.

70. Baas IO, van Rees BP, Musler A, et al. Helicobacter pylori and EpsteinBarr virus infection and the $\mathrm{p} 53$ tumour suppressor pathway in gastric stump cancer compared with carcinoma in the non-operated stomach. $J$ Clin Pathol. 1998;51(9):662-666.

71. Offerhaus GJ, van de Stadt J, Huibregtse K, Tersmette AC, Tytgat GN. The mucosa of the gastric remnant harboring malignancy. Histologic findings in the biopsy specimens of 504 asymptomatic patients 15 to 46 years after partial gastrectomy with emphasis on nonmalignant lesions. Cancer. 1989;64(3):698-703.

72. Palli D, Galli M, Caporaso NE, et al. Family history and risk of stomach cancer in Italy. Cancer Epidemiol Biomarkers Prev. 1994;3(1):15-18.

73. Lauren P. The two histological main types of gastric carcinoma: diffuse and so-called intestinal-type carcinoma. An attempt at a histo-clinical classification. Acta Pathol Microbiol Scand. 1965;64:31-49.

74. Qiu MZ, Cai MY, Zhang DS, et al. Clinicopathological characteristics and prognostic analysis of Lauren classification in gastric adenocarcinoma in China. J Transl Med. 2013;11:58.

75. Ahn HS, Lee HJ, Hahn S, et al. Evaluation of the seventh American Joint Committee on Cancer/International Union Against Cancer Classification of gastric adenocarcinoma in comparison with the sixth classification. Cancer. 2010;116(24):5592-5598.

76. Lauren PA, Nevalainen TJ. Epidemiology of intestinal and diffuse types of gastric carcinoma. A time-trend study in Finland with comparison between studies from high- and low-risk areas. Cancer. 1993;71(10):2926-2933.

77. Ribeiro MM, Sarmento JA, Sobrinho Simões MA, Bastos J. Prognostic significance of Lauren and Ming classifications and other pathologic parameters in gastric carcinoma. Cancer. 1981;47(4):780-784.

78. Amorosi A, Bianchi S, Buiatti E, Cipriani F, Palli D, Zampi G. Gastric cancer in a high-risk area in Italy. Histopathologic patterns according to Lauren's classification. Cancer. 1988;62(10):2191-2196.

79. Sitarz R, Kocemba K, Maciejewski R, Polkowski P. Effective cancer treatment by multidisciplinary teams. Pol Przegl Chir. 2012;84(7):371-376.

80. Ushijima T, Sasako M. Focus on gastric cancer. Cancer Cell. 2004;5(2):121-125

81. Kajitani T. The general rules for the gastric cancer study in surgery and pathology. Part I. Clinical classification. Jpn J Surg. 1981;11(2):127-139.

82. Japanese Gastric Cancer Association. Japanese gastric cancer treatment guidelines 2014 (ver. 4). Gastric Cancer. 2017;20(1):1-19.

83. Ono H, Kondo H, Gotoda T, et al. Endoscopic mucosal resection for treatment of early gastric cancer. Gut. 2001;48(2):225-229.

84. Gotoda T. Endoscopic resection of early gastric cancer. Gastric Cancer. 2007;10(1):1-11.

85. Gotoda T, Yanagisawa A, Sasako M, et al. Incidence of lymph node metastasis from early gastric cancer: estimation with a large number of cases at two large centers. Gastric Cancer. 2000;3(4):219-225.

86. Okines A, Verheij M, Allum W, et al. Gastric cancer: ESMO Clinical Practice Guidelines for diagnosis, treatment and follow-up. Ann Oncol. 2010;21(Suppl 5):S50-S54.

87. Scheidbach H, Lippert H, Meyer F. Gastric carcinoma: when is palliative gastrectomy justified? Oncol Rev. 2010;4(2):127-132.

88. D’Angelica M, Gonen M, Brennan MF, Turnbull AD, Bains M, Karpeh MS. Patterns of initial recurrence in completely resected gastric adenocarcinoma. Ann Surg. 2004;240(5):808-816.

89. Janunger KG, Hafström L, Nygren P, Glimelius B; SBU-group. Swedish Council of Technology Assessment in Health Care. A systematic overview of chemotherapy effects in gastric cancer. Acta Oncol. 2001;40(2-3):309-326.

90. Earle CC, Maroun J, Zuraw L; Cancer Care Ontario Practice Guidelines Initiative Gastrointestinal Cancer Disease Site Group. Neoadjuvant or adjuvant therapy for resectable gastric cancer? A practice guideline. Can J Surg. 2002;45(6):438-446
91. Cunningham D, Allum WH, Stenning SP, et al; MAGIC Trial Participants. Perioperative chemotherapy versus surgery alone for resectable gastroesophageal cancer. $N$ Engl J Med. 2006;355(1):11-20.

92. Polkowski W, Łacko A, Guzel Z. Nowotwory żołądka [Gastric cancers]. In: Krzakowski M, Warzecha K, editors. Zalecenia postepowania diagnostyczno-terapeutycznego $w$ nowotworach złośliwych -2013 rok [Recommendations for Diagnostics and Treatment of Malignant Neoplasms - 2013]. Gdansk: Via Medica; 2013: 119.

93. Ychou M, Boige V, Pignon JP, et al. Perioperative chemotherapy compared with surgery alone for resectable gastroesophageal adenocarcinoma: an FNCLCC and FFCD multicenter phase III trial. J Clin Oncol. 2011;29(13):1715-1721.

94. Waddell T, Verheij M, Allum W, et al. Gastric cancer: ESMO-ESSOESTRO Clinical Practice Guidelines for diagnosis, treatment and follow-up. Ann Oncol. 2013;24 (Suppl 6):S57-S63.

95. Macdonald JS, Smalley SR, Benedetti J, et al. Chemoradiotherapy after surgery compared with surgery alone for adenocarcinoma of the stomach or gastroesophageal junction. $N$ Engl J Med. 2001;345(10): 725-730.

96. Smalley SR, Gunderson L, Tepper J, et al. Gastric surgical adjuvant radiotherapy consensus report: rationale and treatment implementation. Int J Radiat Oncol Biol Phys. 2002;52(2):283-293.

97. Dikken JL, Jansen EP, Cats A, et al. Impact of the extent of surgery and postoperative chemoradiotherapy on recurrence patterns in gastric cancer. J Clin Oncol. 2010;28(14):2430-2436.

98. Van Cutsem E, Van de Velde C, Roth A, et al; European Organisation for Research and Treatment of Cancer (EORTC)-gastrointestinal cancer group. Expert opinion on management of gastric and gastrooesophageal junction adenocarcinoma on behalf of the European Organisation for Research and Treatment of Cancer (EORTC)gastrointestinal cancer group. Eur J Cancer. 2008;44(2):182-194.

99. Wilke H, Stahl M. Therapie beim Magenkarzinom. Aus onkologischer Sicht [Therapy in gastric cancer. From an oncological perspective] Chirurg. 2009;80(11):1023-1027. German.

100. Ott K, Lordick F. Neoadjuvant therapy in the upper gastrointestinal tract. Gastric cancer from a surgical viewpoint. Chirurg. 2009;80(11):1028-1034. German.

101. Wagner AD, Unverzagt S, Grothe W, et al. Chemotherapy for advanced gastric cancer. Cochrane Database Syst Rev. 2010;3:CD004064.

102. Dank M, Zaluski J, Barone C, et al. Randomized phase III study comparing irinotecan combined with 5-fluorouracil and folinic acid to cisplatin combined with 5-fluorouracil in chemotherapy naive patients with advanced adenocarcinoma of the stomach or esophagogastric junction. Ann Oncol. 2008;19(8):1450-1457.

103. Thuss-Patience PC, Kretzschmar A, Bichev D, et al. Survival advantage for irinotecan versus best supportive care as second-line chemotherapy in gastric cancer a randomised phase III study of the Arbeitsgemeinschaft Internistische Onkologie (AIO). Eur J Cancer. 2011;47(15): 2306-2314

104. Kang JH, Lee SI, Lim DH, et al. Salvage chemotherapy for pretreated gastric cancer: a randomized phase III trial comparing chemotherapy plus best supportive care with best supportive care alone. J Clin Oncol. 2012;30(13):1513-1518.

105. Ford HE, Marshall A, Bridgewater JA, et al. Docetaxel versus active symptom control for refractory oesophagogastric adenocarcinoma (COUGAR-02): an open-label, phase 3 randomised controlled trial. Lancet Oncol. 2014;15(1):78-86.

106. Roy AC, Park SR, Cunningham D, et al. A randomized phase II study of PEP02 (MM-398), irinotecan or docetaxel as a second-line therapy in patients with locally advanced or metastatic gastric or gastro-oesophageal junction adenocarcinoma. Ann Oncol. 2013;24(6):1567-1573.

107. Matzinger O, Gerber E, Bernstein Z, et al. EORTC-ROG expert opinion: radiotherapy volume and treatment guidelines for neoadjuvant radiation of adenocarcinomas of the gastroesophageal junction and the stomach. Radiother Oncol. 2009;92(2):164-175.

108. Tey J, Back MF, Shakespeare TP, et al. The role of palliative radiation therapy in symptomatic locally advanced gastric cancer. Int J Radiat Oncol Biol Phys. 2007;67(2):385-388. 
109. Asakura $H$, Hashimoto $T$, Harada $H$, et al. Palliative radiotherapy for bleeding from advanced gastric cancer: is a schedule of 30 Gy in 10 fractions adequate? J Cancer Res Clin Oncol. 2011;137(1):125-130.

110. Bang YJ, Van Cutsem E, Feyereislova A, et al; ToGA Trial Investigators. Trastuzumab in combination with chemotherapy versus chemotherapy alone for treatment of HER2-positive advanced gastric or gastro-oesophageal junction cancer (ToGA): a phase 3, open-label, randomised controlled trial. Lancet. 2010;376(9742):687-697.

111. Wilke H, Muro K, Van Cutsem E, et al. Ramucirumab plus paclitaxel versus placebo plus paclitaxel in patients with previously treated advanced gastric or gastro-oesophageal junction adenocarcinoma (RAINBOW): a double-blind, randomised phase 3 trial. Lancet Oncol. 2014;15(11): 1224-1235.
112. Fuchs CS, Tomasek J, Yong CJ, et al; REGARD Trial Investigators. Ramucirumab monotherapy for previously treated advanced gastric or gastro-oesophageal junction adenocarcinoma (REGARD): an international, randomised, multicentre, placebo-controlled, phase 3 trial. Lancet. 2014;383(9911):31-39.

113. Yang XJ, Huang CQ, Suo T, et al. Cytoreductive surgery and hyperthermic intraperitoneal chemotherapy improves survival of patients with peritoneal carcinomatosis from gastric cancer: final results of a phase III randomized clinical trial. Ann Surg Oncol. 2011;18(6):1575-1581.

114. Glehen O, Gilly FN, Arvieux C, et al. Peritoneal carcinomatosis from gastric cancer: a multi-institutional study of 159 patients treated by cytoreductive surgery combined with perioperative intraperitoneal chemotherapy. Ann Surg Oncol. 2010;17(9):2370-2377.
Cancer Management and Research

\section{Publish your work in this journal}

Cancer Management and Research is an international, peer-reviewed open access journal focusing on cancer research and the optimal use of preventative and integrated treatment interventions to achieve improved outcomes, enhanced survival and quality of life for the cancer patient. The manuscript management system is completely online and includes

\section{Dovepress}

a very quick and fair peer-review system, which is all easy to use. Visit $\mathrm{http}: / / \mathrm{www}$.dovepress.com/testimonials.php to read real quotes from published authors. 